\title{
PANAMÁ: El CRECIMIENTO ECONÓMICO A EXPENSAS DE LA POLÍTICA
}

Panama: Economic Growth at the Expense of Politics

\section{HARRY BROWN ARAÚZ}

Universidad Interamericana de Panamá

\section{CLARA INÉS LUNA VÁSQUEZ}

Centro de Iniciativas Democráticas (CIDEM)

\begin{abstract}
RESUMEN
Igual que en años anteriores, la tasa de crecimiento económico de Panamá en 2012 fue la más alta de toda América Latina. El gobierno panameño está liderado por políticos empresarios que han sabido mantener y aprovechar el impulso que trae la economía panameña, pero que no han controlado los excesos que permiten un sistema político excluyente y un Estado de derecho frágil. La desigualdad económica y la exclusión política han provocado violentas movilizaciones que durante 2012 contrastaron con la bonanza económica y que a simple vista parecen inexplicables. En el texto aquí presentado se plantea que ambos fenómenos, conflictividad y crecimiento económico, están estrechamente relacionados y que, contrario al pensamiento popular, es la economía la que perjudica a la política panameña.
\end{abstract}

Palabras clave: Panamá, crecimiento económico, indígenas, conflictividad, transfuguismo.

\begin{abstract}
As in previous years, Panama's rate of economic growth in 2012 was the highest in Latin America. Panamanian government is led by political entrepreneurs who have managed to maintain and build on the momentum of the Panamanian economy, but who have not been capable of controlling the excesses of an exclusionary political system and of a weak rule of law. Economic inequality and political exclusion have stirred violent protests in 2012 that seem rather inexplicable in the light of the economic boom. This paper suggests that conflict and economic growth are closely related and that, contrary to the popular opinion, what harms Panamanian politics is the economy.
\end{abstract}

Keywords: Panama, Economic Growth, Indigenous People, Political Conflict, Political Turncoatism. 


\section{COYUNTURA ECONÓMICA Y COYUNTURA POLÍTICA PANAMEÑA: EL BINOMIO INDISOLUBLE}

\section{a. Continúa el gran crecimiento económico}

La coyuntura política panameña tuvo sus principales trazos en importantes escándalos de corrupción; los esfuerzos del gobierno para posicionarse ventajosamente para las próximas elecciones y, sobre todo, la movilización, a veces violenta, de estratos de la población marginados económica y políticamente. Aunque la interpretación que dominó la opinión pública fue que las movilizaciones fueron producto de la ausencia de consulta para tomar decisiones, en realidad fueron consecuencia de la disputa por recursos entre la élite económica en el gobierno y parte de la población marginada. En otras palabras, no se trató tanto de deficiencias en el funcionamiento de las instituciones políticas, como de las derivaciones políticas de una dinámica económica trepidante.

La economía panameña continuó mostrando un desempeño destacable en 2012 con relación a sus homólogos de América Latina y muy por encima de los países desarrollados. El Producto Interno Bruto (PIB) creció en 2012 10,6\% con relación al año anterior manteniendo así la tendencia alcista que se registra con dos dígitos desde 2011. Los sectores más dinámicos de la economía fueron la construcción, que al primer trimestre de 2012 creció 27,8\%; la explotación de minas y canteras, que incrementó su valor en $26,7 \%$; y el transporte, almacenamiento y comunicaciones, que aumentó en $13,2 \%$ respecto del primer trimestre del año anterior.

Los sectores que aportaron en mayor medida a la composición del PIB en 2012 fueron el transporte, almacenamiento y comunicaciones, con el 24,9\%; el comercio al por mayor y al por menor, con el 14,1\%; la intermediación financiera, que representa el 9,2\%; y la construcción que contribuye con el 7,6\%. En los últimos años, la construcción se convirtió en uno de los motores de la economía panameña llegando a aportar hasta el 30,69\% del PIB en 2008; sin embargo, desde el 2009 cuando la crisis económica internacional golpeó con mayor fuerza a ese sector, su participación en el valor de la economía disminuyó posicionándose en la actualidad como un sector de importancia media. En cambio, como generador de empleos, la construcción sigue siendo el sector más importante al ofrecer puestos de trabajo a 320 mil panameños, seguido por el comercio que da trabajo a 296 mil personas. Las actividades artesanales de minería, construcción y manufactura emplean a cerca de 194 mil panameños.

El desempleo en 2012 fue solamente de 4\% de la población económicamente activa, mientras que $37,2 \%$ de los trabajadores tienen empleos informales.

En 2012 las construcciones no residenciales alcanzaron el máximo histórico de 751 millones de balboas ( 1 balboa equivale a 1 dólar de los Estados Unidos) impulsadas en gran medida por obras públicas como la construcción de la Línea 1 del Metro de Panamá, la modernización del Aeropuerto Internacional de Tocumen (Ciudad de Panamá), el saneamiento de la Bahía de Panamá, la construcción y ampliación de carreteras y puentes, y la ampliación del Canal de Panamá, entre otras. 
Gráfico 1: Valor del sector de la construcción (2008-2012)

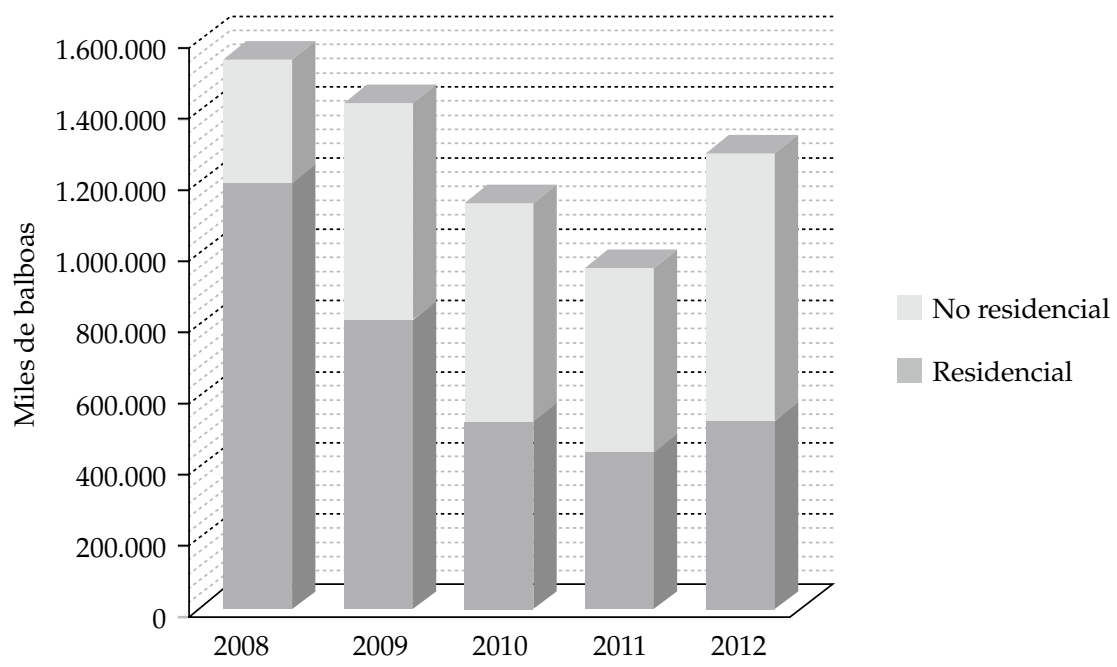

Fuente: Instituto Nacional de Estadística y Censo, 2013.

El crecimiento de la construcción ha desencadenado, por un lado, un incremento de la actividad minera y en canteras para la extracción de materiales de construcción, y por el otro, inflación en los precios de estas materias primas, que repercuten, entre otras, en el valor de la vivienda de interés social. La producción de concreto premezclado creció en 3,4\% a noviembre de 2012.

Reconociendo la evolución de la minería y otras actividades extractivas -crecieron 28,1\% en el primer semestre, aportando al PIB 228,1 millones de balboas-, no se hace raro que estas actividades hayan desencadenado los más importantes conflictos en 2012, teniendo en cuenta que los ngäbe son la etnia indígena que mayor capital social tiene. Los principales minerales extraídos en Panamá son cobre y oro.

La generación de energía también fue motivo de protestas indígenas y campesinas en 2012. En Panamá, las principales fuentes de energía son la hídrica y la térmica. En los últimos años como consecuencia del alza y fluctuación de los precios del petróleo ha habido un fuerte impulso para la generación eléctrica mediante el represamiento de ríos principalmente ubicados en las comarcas indígenas. La generación hidroeléctrica creció en 2012 42\% mientras que la termoeléctrica decreció 14\%. Aunado a este cambio de fuentes de generación, la demanda energética de Panamá está cercana a sobrepasar la oferta disponible de suerte que en el futuro deberá aumentarse rápidamente la capacidad de generación para cubrir el consumo energético de una economía que crece y quiere seguir creciendo y que en 2012 fue de 1.286,5 MW, es decir, solo $34 \mathrm{MW}$ por encima de la producción. En 2012 la demanda de electricidad creció 7,5\%. 


\section{b. El conflicto entre indígenas y gobierno por los recursos naturales}

El conflicto violento entre la etnia Ngäbe-Buglé y el gobierno, que inició el 31 de enero de 2012 con el cierre de la vía Panamericana, en varios puntos, por los indígenas, tuvo su génesis en las movilizaciones que hubo en febrero de 2011 por la reforma al Código Minero que, según los ambientalistas y los indígenas, abría paso a nuevas inversiones mineras que afectarían el medio ambiente. En febrero de 2011 fue firmado el Acuerdo de San Félix, en el que el gobierno aceptó la instalación urgente de una comisión integrada por ellos y la coordinadora indígena y se estableció que se crearía una ley que prohibiría explícitamente la exploración y explotación minera en la comarca indígena, además de la protección de sus recursos hídricos y ambientales. Las protestas de inicios de 2012 fueron provocadas por el incumplimiento de lo pactado, tras la aprobación en primer debate legislativo de lo acordado en San Félix, excepto el artículo clave, el cinco, que explícitamente cancelaba todas las concesiones otorgadas y vigentes para la explotación de recursos minerales y para la construcción de proyectos hidroeléctricos dentro de la Comarca Ngäbe-Buglé, áreas anexas, territorios y comunidades Ngäbe-Buglë fuera de la Comarca.

Las versiones sobre lo acontecido durante el enfrentamiento entre los antimotines y los indígenas movilizados no son claras debido a la dificultad para comunicar lo que allí sucedía luego de la orden que dio el gobierno de suspender las comunicaciones del área de conflicto. En ese momento, las protestas ya se habían extendido a varios puntos del país, incluyendo la Ciudad de Panamá, en donde los indígenas se habían movilizado a pie para llegar hasta los predios de la presidencia de la república. También en ese momento, a los ngäbe se les habían unido otras etnias indígenas. Las protestas dejaron un sinnúmero de heridos, detenidos y dos muertos.

El 7 de febrero de 2012 fue firmado el acuerdo de San Lorenzo. En este acuerdo se ordenó el restablecimiento de la telefonía móvil y el reinicio del diálogo entre el gobierno y la dirigencia ngäbe. El diálogo sería mediado por la iglesia católica y serían observadores la Coordinadora del Sistema de Naciones Unidas, la iglesia evangélica y el rector de la Universidad de Panamá.

Según los datos de encuestas de febrero, al acabar el conflicto violento el gobierno había minado aún más su imagen ante la opinión pública panameña: 80,3\% desaprobó la manera en que manejaron el asunto; $71,8 \%$ consideró que se usó la fuerza de manera injustificada para abrir la vía panamericana; $64 \%$ pensó que la mejor propuesta de diálogo era la de los indígenas; $80,9 \%$ rechazó la explotación de recursos minerales y el 73,5\% rechazó la construcción de hidroeléctricas en la comarca.

El diálogo estuvo estancado durante poco más de un mes, hasta que la facilitación fue asumida por el Sistema de Naciones Unidas. Fue entonces cuando en pocos días surgió un acuerdo político entre el gobierno y la dirigencia ngäbe en el que los primeros se comprometieron a restablecer el régimen especial para la prohibición de la minería y la protección de los recursos hídricos y ambientales en la Comarca Ngäbe-Buglé; la revisión técnica del impacto ambiental de un proyecto hidroeléctrico vigente y la conformación de una mesa nacional para el diseño de un Plan de Desarrollo Integral para los pueblos originarios de la República de Panamá. 


\section{c. Movilización por la descapitalización del Estado en época de gran recaudación}

La siguiente movilización masiva, en junio, fue un poco más compleja aunque confirmó el patrón de levantamientos espoleados por disputas relacionadas con el control, aprovechamiento y distribución de recursos y no por asuntos relacionados con el poder. Esta fue generada por la aprobación sorpresiva en la madrugada del 13 de junio, en segundo debate legislativo, del proyecto de ley 486 que permitiría la venta de las acciones del Estado panameño en las empresas generadoras de energía eléctrica. Dos días más tarde, el 15 de junio, fueron designados los tres magistrados de la Sala Quinta ${ }^{1}$ de la Corte Suprema de Justicia, siendo las tres personas militantes del partido Cambio Democrático, en el poder.

La reacción inmediata en la elite política fue el llamado que hicieron los tres partidos de oposición -Panameñista, PRD y Popular- a unirse en lo que llamaron un "Frente Por la Democracia", para, según dijeron, defender la institucionalidad y el régimen democrático del autoritarismo en ciernes del presidente Martinelli. La unión de los partidos Panameñista y PRD, antiguamente enfrentados durante el régimen autoritario militar y luego adversarios durante 22 años de democracia, no tenía precedentes y fue el rasgo más particular de la coyuntura. El Frente convocó a la ciudadanía a manifestarse frente a la Asamblea Nacional el lunes 18 de junio, día en el que se haría el tercer debate del proyecto de ley 486.

Por primera vez en mucho tiempo los partidos políticos, esta vez de oposición, fueron capaces de articular las demandas de la ciudadanía y movilizarla. Sin embargo, aunque la ciudadanía atendió la convocatoria hecha por los partidos, el común denominador de los convocados fue condicionar su participación a que no aparecieran banderas partidistas en la manifestación pública (La Prensa, 21 de junio de 2012). La articulación de las demandas ciudadanas hecha por los partidos fue aceptada a regañadientes, como si la partidización de la protesta le restara una pretendida pureza. Ciertamente, nadie reconoció el liderazgo efectivo de los partidos de oposición en esa coyuntura, ni siquiera los mismos partidos, temerosos de que al hacerlo se les acusara de querer redituar políticamente el conflicto y quizás hasta de haberlo promovido.

El éxito de la convocatoria hecha por el Frente y el tumulto en las gradas de la Asamblea no impidieron que el ministro de economía intentara presentar a la Asamblea Nacional otro proyecto de ley que posibilitaría la venta de más acciones del Estado, esta vez de

1 La Sala Quinta fue creada en 1998 por el presidente Ernesto Pérez Balladares, miembro del PRD, en la postrimería de su periodo de mandato, principalmente para gestionar las garantías constitucionales a través de los recursos de amparo y hábeas corpus. Otra de sus funciones era resolver las peticiones de los procuradores para la filmación, grabación de conversaciones y comunicaciones telefónicas necesarias para la investigación de delitos graves. Desde su creación prevaleció en la opinión pública el argumento de que con el nombramiento de los tres nuevos magistrados de esta Sala Pérez Balladares buscaba mayoría en el pleno de la Corte Suprema de Justicia para protegerse de cualquier intento de juzgarle una vez dejara la presidencia. Cinco meses después de instalado el nuevo gobierno presidido por la arnulfista Mireya Moscoso, la nueva mayoría legislativa derogó la ley que creó la nueva Sala. La ley que derogó la Sala Quinta recibió cuatro demandas de inconstitucionalidad. Doce años después, en enero de 2011, el pleno de la corte falló a favor de las demandas y declaró inconstitucional la revocatoria de la Sala Quinta, basando su decisión en la independencia de los órganos del Estado. En el fallo se sostiene que la Asamblea podría crear nuevas salas, pero no revocar su creación. 
la compañía telefónica y otras empresas mixtas. Esta sesión fue suspendida cuando algunas personas que protestaban irrumpieron en el hemiciclo en medio de la sesión.

En la coyuntura de junio se mezclaron tres temores con la apertura de una vieja herida. La elite política en la oposición temía que a través de los magistrados de la Sala Quinta el presidente modificara la Constitución para que se le permitiera reelegirse. Visto así, la defensa de la democracia implicaba para los opositores tener la oportunidad de luchar por el poder en 2014 en condiciones normales. Por otro lado, la oposición y la ciudadanía compartían el temor de que los dineros recaudados por la venta de acciones del Estado fueran malversados por un órgano ejecutivo que era percibido como altamente corrupto. Por último, la intención de vender las acciones estatales en empresas públicas hurgó la herida aún abierta por los procesos de privatización de la década de los noventa, ante el temor concreto de la ciudadanía de que aumentara el precio de la energía eléctrica.

El conflicto fue cerrado por el Consejo de Gabinete al dejar sin efecto la resolución con la que habían designado a los tres nuevos magistrados de la Sala Quinta y al desistir el gobierno con el proyecto 486 para la venta de acciones del Estado. No contar con este ingreso provocó un faltante de 400 millones en el presupuesto del país, según advirtió el Ministro de Economía Frank de Lima (La Estrella, 27 de junio de 2012).

A mediados de octubre empezó la discusión en primer debate legislativo del proyecto 529 de regulación de la actividad de la Zona Libre de Colón y permitía la venta de terrenos del Estado panameño en la zona franca. La aprobación del proyecto en primer debate hizo reaccionar a un conjunto amorfo y en buena medida improvisado de organizaciones, educadores y líderes comunitarios que se agruparon en lo que llamaron Frente Amplio por Colón (FAC) para oponerse al proyecto de ley. Por su parte, la Cámara de Comercio, Industrias y Agricultura de Colón rechazó públicamente el proyecto de ley, argumentando que la Zona Libre de Colón podía ser modernizada "sin incluir la injustificada venta del terreno del patrimonio de todos los panameños y de los colonenses" (La Prensa, 19 de octubre de 2012).

La oposición a la privatización de los terrenos de la Zona Libre se dio no porque esta aportara mucho al Estado panameño. El presupuesto general de la nación en 2012 fue de $16.289,9$ millones de balboas, de los que $41 \%$ se destinó a inversión y $8 \%$ al servicio de la deuda. El gobierno central gozó de la mayor porción de ese presupuesto acumulando $8.529,4$ millones de balboas, seguido de las instituciones descentralizadas que se adjudicaron 4.264,9 millones de balboas, las empresas públicas sumaron 3.271,1 millones de balboas y los municipios obtuvieron los restantes 224,6 millones de balboas. En 2012, el Estado recaudó por concepto de impuestos cerca de 3.900 millones de balboas, 973 millones de balboas de participación en las utilidades de empresas públicas y mixtas, y solo 66,6 millones de dólares fueron los ingresos percibidos por el gobierno desde la Zona Libre de Colón, que en el mismo periodo tuvo una actividad económica por importaciones y reexportaciones que sumó 29.164 millones de dólares. 
Gráfico 2: Distribución del Presupuesto de la Nación 2012

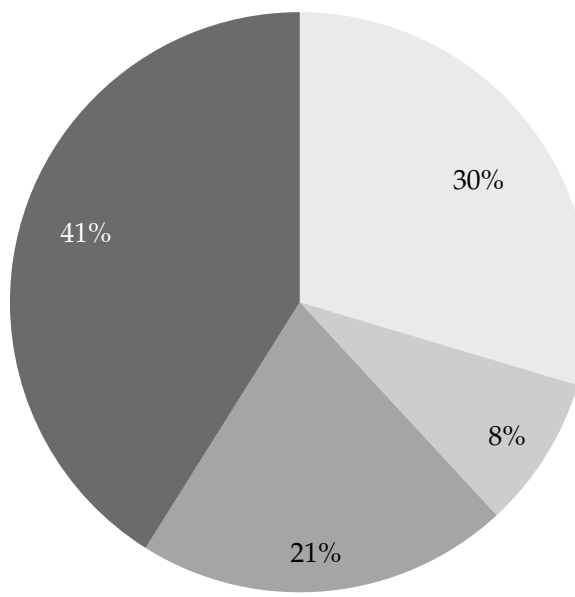

Instituciones

Servicio de la deuda

Transferencias corrientes, subsidios y aporte al fisco

Inversión

Fuente: Instituto Nacional de Estadística y Censo, 2013; y Presupuesto del Sector Público, 2012.

Al inicio, las protestas consistieron en cerrar las calles de la Ciudad de Colón y fueron dispersadas violentamente, primero por unidades especializadas de la Policía Nacional y posteriormente por unidades del Servicio Nacional de Fronteras, entrenadas para enfrentar grupos insurgentes armados apostados en el límite entre Panamá y Colombia. Luego, tras casi dos semanas de protestas y un paro de cuatro días en Colón, la movilización incluyó a otras organizaciones en otras regiones del país: el Sindicato Único de Trabajadores de la Construcción y Similares (SUNTRACS), que bloqueó la circulación en unos siete puntos de la Ciudad de Panamá e indígenas de la etnia ngäbe cerraron algunas vías en la provincia de Chiriquí.

La coyuntura fue manejada erráticamente por el gobierno. El Presidente de la República estuvo de gira por Europa y Asia durante todo el conflicto, sólo una semana después de iniciados los disturbios el presidente publicó vía Twitter que retiraría el proyecto, al tiempo que el ministro de economía declaraba públicamente que no sería retirado. Varios miembros importantes del gobierno se desplazaron formalmente a la provincia de Colón para iniciar un diálogo con la dirigencia del FAC y fueron plantados más de una vez. A pesar de lo prolongado y fuerte de las protestas, la ley fue aprobada, lo cual solo sirvió para arreciarlas. Aunque el ministro de la presidencia anunció la derogación de la ley, las protestas continuaron hasta que el presidente volviera y firmara la derogación. La coyuntura fue cerrada luego de que el SUNTRACS empezó a tomar control del descontento ciudadano y paralizara la Ciudad de Panamá, en medio del vandalismo y el saqueo del comercio de personas que no fueron identificadas. El gobierno derogó la ley y convocó a un diálogo con el FAC que desde el inicio evidenció que difícilmente lograría acuerdos. La represión sufrida por los manifestantes durante dos semanas de protestas dejó tres muertos y un número no calculado de heridos y detenidos. 
El FAC logró movilizar a la ciudadanía colonense y a la opinión pública del país a su favor. Según la encuesta de Dichter and Neira de noviembre, el 86\% de la población desaprobó la forma de proceder del gobierno en Colón, y la aprobación de la labor del presidente Martinelli cayó de $60 \%$ a $41 \%$ en solo un mes.

\section{d. El conflicto institucional entre el órgano ejecutivo y el Tribunal Electoral}

Las movilizaciones ciudadanas en contra de decisiones y sus posteriores revocos evidenciaron un gobierno con poca credibilidad y escaso capital político. Es de esperarse que si continúan esas condiciones al partido de gobierno le sea más difícil afrontar con razonables expectativas de éxito las próximas elecciones. Sabiendo esto, el gobierno hizo durante todo 2012 importantes esfuerzos para posicionarse de facto ventajosamente en las elecciones de 2014.

Bajo esa óptica se pueden entender las fricciones que hubo entre el Tribunal Electoral y el Órgano Ejecutivo durante 2012. Insólitamente, en febrero el Magistrado Presidente del Tribunal Electoral, Gerardo Solís, advirtió en nombre de los tres magistrados que las elecciones de 2014 podrían ser fraudulentas (La Prensa, febrero de 2012).

En mayo, con la autorización del presidente Martinelli, un abogado de Cambio Democrático presentó una demanda ante la Corte Suprema en la que pidió la separación y destitución de los tres magistrados del Tribunal Electoral por el caso de las elecciones en el corregimiento de El Bebedero, donde no se reconocía a la ganadora de dichos comicios. Un mes después el Presidente de la República retiró la denuncia (La Estrella, 23 de junio de 2012). También en junio, el Tribunal Electoral se negó a corregir las fechas de vencimiento de las credenciales de siete miembros del partido oficialista que fueron elegidos como diputados al PARLACEN.

En agosto, el Tribunal Electoral anuló las elecciones extraordinarias en el corregimiento de El Bebedero en las que había ganado la candidata de Cambio Democrático. Según el fallo del Tribunal Electoral, la candidata oficialista había sido beneficiada con el uso de fondos públicos directos e indirectos recibidos a través de donaciones de contratistas del Estado (La Estrella, 17 de agosto de 2012).

Ya entonces los magistrados del Tribunal Electoral hacían pública su incomodidad con el órgano ejecutivo e incluso denunciaban estar siendo presionados institucionalmente a través de la demora en el flujo de caja para la construcción del nuevo edificio del Tribunal Electoral. En ese sentido, en septiembre el magistrado Erasmo Pinilla denunció una campaña para desprestigiarlo. Le acusaron de tener en la planilla del Tribunal Electoral a su hermana, sobrinos, cuñados y primos y de usar recursos de la institución para asuntos particulares.

Con este ambiente fueron discutidas en la Asamblea Nacional las reformas al Código Electoral, con la discrepancia de los partidos de oposición y la sociedad civil, que clamaban por nuevas normas consensuadas con ellos. Sin embargo, la bancada de gobierno hizo prevalecer su mayoría absoluta en medio de escaramuzas puntuales afuera del palacio legislativo. La nueva ley sancionada el 17 de septiembre reformó seis artículos y agregó 
tres nuevos artículos al Código Electoral vigente. En esos nueve artículos fueron cuatro los asuntos abordados: la apertura del proceso electoral y momento para la realización de las primarias; requisitos para la libre postulación presidencial; las postulaciones interalianzas y la adjudicación de escaños en las alianzas, promoción de postulaciones de mujeres y la eliminación del voto "en plancha".

La mayoría que tiene en el hemiciclo el gobierno y que aprobó las reformas electorales no habría sido lograda sin el cambio de partido que han hecho 28 diputados de partidos de oposición hacia el partido Cambio Democrático, principalmente, y en menor medida al Movimiento Republicano Nacionalista (MOLIRENA). Entre enero y abril de 2012 hubo seis tránsfugas más, cinco de ellos miembros originalmente del Partido Panameñista que se inscribieron en el MOLIRENA, aunque sin ellos la bancada oficialista ya tenía mayoría absoluta.

La conducta discrecional en el manejo de las instituciones propicia la corrupción en todos los ámbitos del gobierno. Según el Índice de Percepción de la Corrupción 2012 elaborado por la organización Transparencia Internacional, Panamá se encuentra en el lugar 83 de 176 países, con un índice de 38 en una escala que va de 0 a 100. En abril de 2012, la opinión pública panameña conoció el contenido de una conversación telefónica entre el exdirector comercial de la empresa italiana Finmeccanica y Valter Lavitola, colaborador del entonces presidente italiano Silvio Berlusconi, en la que se mencionó al presidente Martinelli como beneficiario de un soborno de 30 millones de dólares por la compra de unas cárceles modulares que haría una empresa italiana al gobierno panameño.

En julio otra grabación circuló por las redes sociales y los noticieros del país. Nuevamente el presidente Ricardo Martinelli, junto con el ministro de la presidencia, era involucrado en un hecho de corrupción, esta vez por la titulación espuria de terrenos adyacentes a la playa Juan Hombrón. El abogado Raúl Mata, protagonista de la grabación, fue quien supuestamente consiguió que las tierras aparecieran a nombre de los padres del ministro de la presidencia, Papadimitriu.

A principios de agosto hubo un curioso conflicto político entre dos empresas privadas, siendo que aparentemente una de ellas estaba utilizando el poder político a su favor. Como reacción a una serie de reportajes que hizo el diario La Prensa denunciando la obtención de contratos públicos por la empresa Transcaribe Trading (TCT) gracias al tráfico de influencias directas con el Presidente de la República, camiones de la empresa bloquearon la entrada de las oficinas del diario para impedir su circulación. Supuestamente, los trabajadores actuaron por iniciativa propia y exigían que hubiera derecho a réplica para los dueños de la empresa. Los opositores del gobierno interpretaron el hecho como un acto más del órgano ejecutivo que atentaba contra la libertad de expresión, al argumentar que la pasividad de la policía era prueba del contubernio entre el presidente Martinelli y los dueños de TCT. 


\section{PODER EJECUTIVO: LA RENUNCIA DEL SUPERMINISTRO, MÉRITOS EXTRAPOLÍTICOS Y “DECISIONISMO” IMPULSIVO}

A mediados de 2012, el 13 de julio, el Ministro de la Presidencia Demetrio Papadrimitriu renunció al cargo. Esta renuncia era, sin duda, la más sensible que podía haber en el gobierno presidido por Ricardo Martinelli. Papadimitriu fue el jefe de las campañas presidenciales del candidato Martinelli en 2004 y 2009, se le reconocía como la persona más cercana al presidente y era llamado "el superministro". La importancia y liderazgo de Papadimitriu dentro del gabinete fue confirmada desde el inicio, cuando se responsabilizó de dos temas muy sensibles políticamente, que de manera normal pertenecían a otras carteras: la construcción de una primera línea de metro en la Ciudad de Panamá y la transformación del transporte público también en la Ciudad de Panamá.

Como se podía esperar, Papadimitriu justificó su salida con parquedad argumentando que era el momento de que otras personas se encargasen de los asuntos que él había estado manejando (La Estrella, 13 de julio de 2012). Sin embargo, con certeza el ministro renunció el mismo día en que fue publicado el decreto ejecutivo que ordenó la expropiación sin indemnización de 54 hectáreas en una playa que, supuestamente, habían sido compradas espuriamente por sus padres (La Prensa, 14 de julio de 2012). Este asunto se había convertido en uno de los principales escándalos de corrupción del gobierno.

Después de salir Papadimitriu fue designado como Ministro de la Presidencia Roberto Henríquez, quien hasta ese momento había sido Ministro de Relaciones Exteriores y antes Ministro de Comercio e Industrias. A Henríquez le reemplazó Rómulo Roux, quien fue hasta ese momento Ministro de Asuntos del Canal. A Roux le reemplazó Roberto Roy, un prestigioso y exitoso ingeniero que hasta ese momento había estado encargado de la construcción de la primera línea de metro de la Ciudad de Panamá.

Estas designaciones fueron anunciadas formalmente por el presidente Martinelli el 14 de agosto, un mes después de la salida de Papadimitriu. Fue entonces cuando, además de las ya conocidas, fueron anunciadas las salidas del Ministro de Obras Públicas, José Suárez, y el Ministro de Salud, Franklin Vergara. Respectivamente, fueron reemplazados por el entonces Viceministro de Vivienda, Jaime Ford, y Javier Díaz, Director de prestaciones médicas de la Caja de Seguro Social.

Estos cambios en el gabinete no solo parecían ajustes hechos a raíz de la salida de Papadimitriu, sino que también parecieron la respuesta a la caída de la popularidad del Presidente, que ese mes había obtenido el índice más bajo desde que había iniciado su gestión, 21\% de aprobación, según encuesta de la firma Ipsos publicada por el diario La Estrella (4 de agosto de 2012).

Aunque todos los ministros salientes, entrantes y rotados tienen estudios universitarios completos, excepto José Suárez, los antecedentes académicos y su desempeño profesional tienen poco que ver con los méritos para sus designaciones -quizás la única excepción es Roberto Roy-. Asimismo, aunque todos, excepto Roy, son miembros del partido Cambio Democrático, solo Roberto Henríquez es reconocido como un militante orgánico y disciplinado de su partido, por lo que la militancia tampoco es el primer criterio para 
la elección. Todos, excepto Franklin Vergara, se proyectan como empresarios, más que como políticos, aunque hagan política.

En 2009, Martinelli se presentó ante el electorado como un candidato antipolítica, cuyo principal mérito era ser un empresario exitoso que, lógicamente, se haría acompañar de empresarios que llevaran sus métodos de trabajo y estándares de eficiencia a la administración pública (Brown Araúz y Rosales Valladares, en prensa). En ese sentido, al presidente le caracteriza un estilo "decisionista" que sus opositores denuncian como "autoritario". Ciertamente, los tiempos de la política y de la administración pública son una camisa de fuerza insoportable para un presidente que solamente, más que ningún otro, quiere ser valorado por las decisiones y por sus resultados, no por la legitimidad de lo decidido.

El estilo presidencial, además de "decisionista", es impulsivo. Una buena muestra de esa impulsividad fueron las declaraciones hechas por el presidente en algunos de sus viajes oficiales. La política exterior panameña tuvo durante 2012 como rasgo más importante la promoción del país como espacio privilegiado para la inversión extranjera o, como suelen decir miembros del gobierno, incluido el presidente, "vender el país". Durante la visita que realizó el presidente a Alemania en octubre, sorpresivamente declaró que Panamá estaba buscando mecanismos para que el euro fuera moneda de circulación legal en el país. Esa declaración, aunque disparatada, no fue tan grave como la hecha en Japón una semana después, al apoyar la reclamación hecha por ese país a China por el archipiélago Senkakyu, lo que desató la reacción del gobierno chino pidiendo a Panamá no menoscabar los intereses de Hong Kong.

Ambos desaciertos descritos se sumaron a otros dos, ambos del año 2010. En una visita a Israel, el presidente declaró que ese país era el guardián de la ciudad santa, lo que desató las críticas de políticos palestinos que catalogaron lo dicho como una ofensa a todo el mundo árabe, al mundo islámico y cristiano y al derecho internacional. Luego, de visita en Perú, la opinión pública peruana acusó al presidente panameño de intervenir en la política interna después que este invitara a los empresarios del país a hacerse con el poder político, como hizo él, porque son la única salvación de su país.

\section{PODER LEGISLATIVO: LA CONSOLIDACIÓN DE UNA MAYORÍA LEGISLATIVA DE TRÁNSFUGAS}

Durante 2012, uno de los hechos más visibles en la Asamblea Legislativa para la opinión pública panameña, fue el transfuguismo. En 2012 hubo seis nuevos tránsfugas, que se sumaron a los 22 que desde 2009 han abandonado sus partidos para adherirse a la bancada de gobierno. ${ }^{2}$

2 Aunque hubo tránsfugas en 2009, la ola de transfuguismo comenzó en abril de 2010 justo después de que la bancada de gobierno aprobó el endurecimiento del procedimiento para aplicar la revocatoria de mandato a los diputados indisciplinados. 
Los seis nuevos tránsfugas provinieron del Partido Panameñista. Distinto a lo que hicieron los veintidós anteriores, que se inscribieron en el partido Cambio Democrático del presidente Ricardo Martinelli, éstos se pasaron al MOLIRENA, el partido aliado de Cambio Democrático. Es importante tener en cuenta que cuando fue endurecido el procedimiento para aplicar la revocatoria de mandato el Partido Panameñista era aliado de Cambio Democrático y uno de sus miembros más importantes presidía la Asamblea. Según el diario La Prensa (25 de septiembre de 2012), el transfuguismo ha sido promovido desde el órgano ejecutivo, principalmente, usando fondos del Programa de Ayuda Nacional (PAN).

Con los cambios habidos, la Asamblea Nacional en 2012 quedó distribuida así: 37 diputados en la bancada del partido Cambio Democrático; 17 en la bancada del PRD; uno en la bancada del Partido Popular; seis en el MOLIRENA y diez en la bancada del Partido Panameñista. Vale la pena recordar que el resultado de las elecciones legislativas de 2009 había otorgado 14 diputados al partido Cambio Democrático; 26 al PRD; uno al Partido Popular; dos diputados al MOLIRENA; cuatro al partido Unión Patriótica; dos postulados libremente; uno al partido Vanguardia Moral de la Patria y 21 al Partido Panameñista.

Tabla 1. Distribución de la Asamblea Nacional en 2009 y 2012

\begin{tabular}{|c|c|c|}
\hline Partido & 2009 & 2012 \\
\hline Partido Panameñista & 22 & 10 \\
\hline Cambio Democrático & 13 & 37 \\
\hline PRD & 26 & 17 \\
\hline Partido Popular & 1 & 1 \\
\hline MOLIRENA & 2 & 6 \\
\hline Unión Patriótica & 4 & - \\
\hline Vanguardia Moral de la Patria & 1 & - \\
\hline Libre postulación & 2 & - \\
\hline Total & 71 & 71 \\
\hline
\end{tabular}

Fuente: elaboración propia

Con este panorama no es raro que el órgano legislativo en la práctica haya cedido la iniciativa legislativa al órgano ejecutivo y que sus proyectos sean absolutamente prioritarios. Según datos de la Unidad de Estadísticas de la Secretaría General de la Asamblea Nacional, del total de proyectos presentados por los órganos del Estado, 57\% fueron presentados por el órgano ejecutivo y $41 \%$ por el órgano legislativo; de todas las leyes sancionadas, el $76 \%$ fueron las del órgano ejecutivo y 20\% las del órgano legislativo. 


\section{RELACIÓN ENTRE LOS PODERES DEL ESTADO}

En 2012, una porción pequeña de la ciudadanía panameña opinó que los órganos legislativo y judicial son independientes del órgano ejecutivo. Así lo revelaron las encuestas de abril, agosto y diciembre hechas por la firma Dichter and Neira. En cada uno de esos meses, solamente el 22\%, 17\% y 20\% de los encuestados dijo que la Asamblea Nacional "actúa con independencia del órgano ejecutivo", mientras que para el órgano judicial los porcentajes fueron de $23 \%, 19 \%$ y $21 \%$, respectivamente.

Casi desde el inicio del periodo presidencial, una de las principales críticas que ha hecho la oposición partidista y la opinión pública al presidente Ricardo Martinelli ha sido su propensión al autoritarismo y, precisamente, su recurrente intromisión en la gestión del órgano legislativo y el judicial. En 2012 no fue distinto y las críticas de intromisión, apoyadas básicamente en la denuncia del transfuguismo descrito en el parágrafo anterior, en la elección del presidente del órgano legislativo y la desconfianza en el método para la elección de magistrados de la Corte Suprema de Justicia.

A fines de 2012 fue elegido un nuevo magistrado para la Corte Suprema de Justicia, que iniciaría su periodo en enero de 2013. La designación hecha por el consejo de gabinete el 18 de diciembre recayó sobre José Ayú Prado, quien fungía como procurador de la nación hasta el momento que fue ratificado, días después, por la Asamblea Nacional. Al mismo tiempo, al quedar el cargo vacante, fue designada como procuradora la abogada Ana Belfon, quien hasta ese momento fue jefa de asesoría legal de la presidencia de la república. Según notas del diario La Prensa del 11 y del 19 de diciembre de 2012, la opinión pública rechazó los nombramientos de Ayú y Belfon debido a la ausencia de transparencia de los procesos para la designación en ambos casos y, en el caso de Belfon, por su cercanía política actual con el presidente Martinelli y su relación con el régimen autoritario encabezado por Manuel Antonio Noriega.

La percepción de intromisión del órgano ejecutivo en otros poderes y otras ramas del Estado no se limitó a los órganos legislativo y judicial. La elección de un nuevo magistrado para el Tribunal Electoral también estuvo llena de cuestionamientos a la transparencia del proceso y denuncias de que la designación había sido manipulada por el Presidente de la República para favorecerse personalmente o a su partido en las elecciones generales de 2014, hechas por la sociedad civil y los partidos políticos de oposición. La elección, hecha por la Corte Suprema de Justicia, de la que como se ha visto se duda de su independencia, cayó sobre Heriberto Araúz, un profesor universitario, doctor en derecho, a quien no se le conoce pasado partidista y sin vínculos evidentes con el Presidente de la República.

Por último, en la alcaldía de Panamá hubo fuertes evidencias de que el órgano ejecutivo buscó intervenir en las decisiones que allí se toman. El 12 de enero de 2012 el entonces alcalde del distrito de Panamá, el panameñista Bosco Vallarino, renunció al cargo por problemas de salud, según la carta enviada a la gobernadora de la provincia de Panamá. Sin embargo, según versiones dadas por miembros del Partido Panameñista recogidas por la prensa local, Vallarino renunció debido a las amenazas recibidas de parte del 
presidente Martinelli en una reunión que hubo dos días antes. Al ex alcalde le sucedió la vicealcaldesa Roxana Méndez, miembro de Cambio Democrático que en ese momento fungía como ministra de gobierno y quien fue candidata a vicepresidenta de la república en la primera postulación presidencial de Martinelli en 2004.

\section{EVALUACIÓN GENERAL SOBRE EL FUNCIONAMIENTO Y CALIDAD DE LA DEMOCRACIA}

Según el Índice de Desarrollo Democrático de América Latina (IDD-LAT), en 2012 la democracia panameña era la cuarta más avanzada de toda la región, detrás de Costa Rica, Chile y Uruguay. Este dato no debe sorprender, ya que durante los últimos diez años ha sido así casi invariablemente, con todo y que desde 2010 Panamá bajó su clasificación a país con desarrollo democrático "medio".

La democracia panameña ha aprendido a contar votos y a respetar la voluntad popular transmitida a través del sufragio y ha logrado tener un país políticamente estable, de manera que se ha hecho atractivo para la inversión privada local y extranjera. No obstante, paradójicamente esa estabilidad ha sido lograda excluyendo a buena parte de la población de las decisiones políticas a través del sistema de representación. Como es de esperarse, la exclusión trae con el tiempo abuso de los incluidos y la insatisfacción de los excluidos. Ambas consecuencias fueron evidentes y se entrelazaron durante 2012.

Aunque en este texto no se ha pretendido evaluar exhaustivamente el desempeño de la democracia panameña, se planteó una hipótesis con la que se obtendría una línea argumental que permitiera elegir no los hechos aparentemente más visibles y comentados, sino los asuntos fundamentales del acontecer panameño de 2012. Usualmente, al menos en Panamá, la opinión pública lamenta que la política frena y eventualmente podría hacer daño grave a la economía. No obstante, una mirada un poco más cuidadosa y quizás menos prejuiciada de los procesos socioeconómicos panameños dan sentido a la hipótesis de que la dinámica económica trepidante del país perjudica la calidad de su política.

El recurrente conflicto con los indígenas ilustra bien esa hipótesis. El capital panameño necesita, a como dé lugar, que el país produzca más energía para seguir creciendo y, además, la elite panameña ha descubierto en la extracción de minerales una dinámica y creciente fuente de riqueza. Los tiempos económicos, veloces y aplastantes, no dan espacio ni permiten tomar en cuenta a los excluidos entre los excluidos panameños, los indígenas, que están justo allí donde descansan los recursos deseados. La política exige tomarse el tiempo para incluir a los afectados en las decisiones pertinentes, con el propósito de legitimarlas y de que la riqueza producida sea fuente de bienestar general. Además, si las decisiones son compartidas, cabría la posibilidad de que se decidiera no explotar esos recursos. La economía no puede permitirse eso y se intentó pasar por encima de los indígenas.

Es posible que sólo con esa lógica de pensamiento pueda explicarse que un país con pleno empleo, altas tasas de crecimiento y disminución del índice de pobreza, las movilizaciones conflictivas sean tan violentas, al tiempo que el gobierno parece sólo preocupado por 
hacer negocios y es esencialmente incapaz de conectarse con la necesidad de equidad política y económica del país que gobierna.

\section{REFERENCIAS}

Brown Araúz, Harry y Rotsay Rosales, 2013. “Cambiar todo para que nada cambie: los inside-outsiders de América Central". En prensa.

Diario La Estrella, 2012, varias ediciones en línea.

Diario La Prensa, 2012, varias ediciones en línea.

Konrad Adenauer Stiftung, 2012. “Índice de Desarrollo Democrático de América Latina” [en línea]. http:/ / www.idd-lat.org/downloads/idd-lat-2012.pdf

Instituto Nacional de Estadística y Censo, 2012, 2013. “Principales indicadores” [en línea]. http:/ /www. contraloria.gob.pa/inec/

Harry Brown Araúz. Doctor en Ciencias Políticas y Sociología por la Universidad Complutense de Madrid. Investigador asociado del Centro de Iniciativas Democráticas (CIDEM). Sus temas de interés son los partidos políticos y los sistemas de partidos, las elecciones y los procesos de reforma electoral. E-mail: hbrownarauz@laureate.edu.pa

Clara Inés Luna Vásquez. Maestra en Comunicación por la Universidad Autónoma de México. Investigadora asociada del Centro de Iniciativas Democráticas (CIDEM). Sus temas de interés son comunicación política y economía política de la comunicación y la cultura.

E-mail: clarai_luna@hotmail.com 
